Revista de Derecho

Universidad Católica del Norte

Sección: Estudios

Ańo 18 - No 2, 2011

pp. $137-149$

\title{
LA RESPONSABILIDAD CIVIL DE LOS NOTARIOS EN CHILE
}

\section{Carlos Pizarro Wilson ${ }^{*}$}

RESUMEN: La responsabilidad civil que puede recaer en los notarios constituye un tema inexplorado en Chile, sin que haya existido inquietud doctrinal ni jurisprudencial sobre la materia. Esto contrasta con la participación de los notarios en negocios simples y complejos en que no solo ejecuta sus labores encomendadas por la ley, sino que se extiende a consejos y entrega de información, siendo necesario determinar qué conductas pueden originar una indemnización de perjuicios y bajo qué estatuto corresponde situar dicha responsabilidad civil.

PaLABRAS CLAVE: Responsabilidad civil - notarios - instrucciones notariales.

\section{LIABILITY OF THE NOTARIES IN CHILE}

ABSTRACT: The liability that might fall on the notaries represents an unexplored topic in Chile, without the existence of prior doctrinal or jurisprudential concern over the matter. This is a contrast compared to the notaries' participation in simple and complex businesses where not only does he execute his duties by law, but also extends to advice and delivery of information, making it necessary to determine what behavior might initiate a loss compensation and under what statute shall that liability be located.

KEY WORDS: Liability - notaries - notary instructions.

\section{INTRODUCCIÓN}

En nuestro país la responsabilidad civil de los notarios es un misterio $^{1}$. No hay doctrina disponible que se ocupe del asunto, ni tampoco se

* Doctor en Derecho y profesor de Derecho Civil de la Universidad Diego Portales (Chile). Correo electrónico: carlos.pizarro@udp.cl

Fecha de recepción: 16 de junio de 2011.

Fecha de aceptación: 19 de julio de 2011.

1 Ver sin embargo, Peña Torres, J. Y Velozo Alcalde, J. (2007). Auxiliares de la administración de justicia: ¿monopolios de privilegio? Disponible en: http://www.economiaynegocios. 
ha presentado en la práctica jurisprudencial una inquietud al respecto ${ }^{2}$. Como es evidente, no existe ninguna legislación particular sobre la materia. No existen artículos de Doctrina, ni monografías, tampoco se encuentran sentencias específicas sobre esa problemática, y la ausencia de un estatuto especial de responsabilidad civil es clara ${ }^{3}$.

Esto contrasta con el desarrollo moderado en otros ámbitos de la responsabilidad profesional. Piénsese en el ingente crecimiento de demandas en el área de la salud contra médicos ${ }^{4}$ o, aunque en menor medida, la responsabilidad profesional del abogado que ya comienza a manifestarse en los tribunales 5 .

En contraste con esta ausencia de responsabilidad, la profesión del notariado ha ido adquiriendo una función cada día más relevante en los pequeños y grandes negocios, sobre todo en el ámbito del derecho de sociedades y aquel inmobiliario y sucesorio. En el ejercicio de sus funciones convive con el ciudadano común y con abogados, incluso facilitando modelos de contratos y consejos para aquellos desprovistos de asesoría jurídica, lo que se acrecienta en las zonas rurales o aisladas. Ante la ausencia de una normativa especial, no puede sino construirse una responsabilidad civil de los notarios, como ha ocurrido en el extranjero, a partir del derecho común de la responsabilidad civil. Lo que conlleva considerar las

uahurtado.cl/wp/wp-content/uploads/2010/06/pdf-observatorio-n7.pdf [fecha de visita 21 de marzo de 2001]. Aunque el trabajo coloca el énfasis en sus aspectos económicos. Dos memorias se han consagrado en términos monográficos al notariado, sin referirse en términos específicos a la responsabilidad civil. Henríquez Marino, Óscar (s/a) Nociones generales del notario en Chile. Santiago: Universidad de Chile, 84 pp.; Baeza Banderas, Enrique (1924) El notario. Santiago: Universidad de Chile, 79 pp. Una memoria sobre la cuestión, Leyton Guerrero, Cristian (2005) La responsabilidad del notario. Santiago: Universidad Católica de Chile, 225 pp.

2 No se encontraron sentencias en las bases usuales de jurisprudencia local, utilizando descriptores pertinentes. Se revisó LegalPublishing, Mircrojuris y Westlaw Chile. En esta última existen sentencias relativas a responsabilidad disciplinaria de los notarios. En particular Corte de Apelaciones de Temuco, 26 de marzo de 2010, CL/JUR/6476, rechazándose la queja; Corte de Apelaciones de Antofagasta, 21 de enero de 2008, CL/JUR/748/2008, en que se discute la responsabilidad del notario titular por un hecho del notario suplente, estimándose que ese tipo de responsabilidad disciplinaria es de naturaleza individual, rechazándose la queja; Corte de Apelaciones de Santiago, 22 de septiembre de 2009, CL/ JUR/1249/2009, en que se desecha la demanda por responsabilidad extracontractual contra un notario por protesto de pagaré en que intervino.

3 Esto contrasta con la experiencia comparada, en Francia el libro de referencia es Aubert, J.-L. (2008) La responsabilité civile des notaires. 5 a edición por Richard Crône. Paris: Defrénois-lextenso, $164 \mathrm{pp}$. En este texto se cita abundante bibliografía sobre el tema.

4 Sobre responsabilidad médica existen hoy trabajos académicos, entre otros véase, AA.VV. ((2010) Responsabilidad médica. Cuadernos de Análisis Jurídico. Santiago: Universidad Diego Portales, 221 pp., que reúne un compendio de artículos sobre la materia.

5 Véase el excelente artículo dedicado a la responsabilidad de abogados en el derecho español, Crespo Mora, Ma Carmen, (2009). "Algunos aspectos problemáticos de la responsabilidad civil de los abogados en Derecho español". Revista Chilena de Derecho Privado. No 12, pp. 101-133, p. 101. 
particularidades de la profesión del notariado. El trazo más distintivo de la profesión radica en su calidad de ministro de fe, testigo privilegiado y su función de autentificar documentos, cuyo sello importará la fuerza ejecutiva, destinada a facilitar el cobro ante los tribunales de justicia a partir de un documento indubitado. A estas funciones clásicas, al menos en el concierto comparado, se le ha ido agregando un verdadero deber de consejo e información ${ }^{6}$.

Siendo un tema poco explorado en el derecho nacional, resulta pertinente interrogarse sobre las hipótesis que conllevarían responsabilidad del notario, lo que nos arrastra a un intento de delimitar los deberes y obligaciones a su cargo, cuya infracción importará responsabilidad civil si concurren los elementos indispensables para otorgar una indemnización, siendo pertinente ahí auscultar el régimen de responsabilidad aplicable.

\section{1) DEBERES U OBLIGACIONES DE LOS NOTARIOS}

El problema de los deberes u obligaciones que atañen al notario tampoco han inquietado a la doctrina local. Al no existir una sistematización de los deberes a cargo de los notarios debemos recurrir a las fuentes usuales de las obligaciones. Aquí corresponde concentrarse en aquellas obligaciones típicas de la actividad notarial, cuya presencia es identitaria del cargo de notario público.

La función notarial o su presencia para determinados actos viene explicitada en la ley. En estas hipótesis, la responsabilidad se derivará de una culpa infraccional, si el notario no ha realizado la función que le reconoce el texto legal en la forma correcta. Junto a esta responsabilidad por culpa infraccional puede darse aquella menos precisa, pero más amplia, por haber incurrido el notario en un comportamiento alejado de su lex artis.

\section{(1.1) FUNCIONES RECONOCIDAS EN LA LEY}

La legislación establece cuáles son los actos que deben ejecutar los notarios para dar fuerza probatoria y ejecutiva a los instrumentos que autentifica y las responsabilidades administrativas para la gestión de los documentos de su oficio. De ahí la relevancia de auscultar los textos legales que se refieren a la función notarial. Sin duda el Código Orgánico de Tribunales -COT-, constituye el recipiente fundamental, siendo los artículos 399 y siguientes el contenido esencial de las obligaciones que asumen los notarios. Interesa también el Código de Procedimiento Civil -CPC-,

$6 \quad$ Aubert, (2008) 110. 
pues ahí se reconocen funciones específicas a los notarios, aunque no siempre de manera exclusiva ${ }^{7}$. Por cierto el Código Civil es también una fuente relevante, al considerar la autentificación como solemnidad para muchos casos. Para todos los actos solemnes, cuya formalidad esté radicada en la necesidad de escritura pública, la presencia del notario es esencial para la perfección de los actos.

Además, el fenómeno de descodificación ha importado que la regulación de actos civiles sea objeto de leyes especiales y, en no pocos casos, se requiere también la intervención del notario.

En particular, es relevante el artículo 401 del COT que especifica las funciones del notario, si lo hace mal, eso que se describe ahí, habrá incumplimiento y culpa infraccional, acarreando responsabilidad civil si se han suscitado daños. Esta y otras reglas que describan lo que el notario debe hacer constituyen fuente clara de responsabilidad.

El notario siempre ha estado atado a una función autentificadora, al conferir a determinados documentos fuerza probatoria y ejecutoria. Si bien es un funcionario público algo extravagante, en el sentido que no es remunerado por el Estado, sino por sus clientes, queda supeditado al control disciplinario de las respectivas Cortes de Apelaciones. Así están definidos por el COT, al expresar que se trata de "ministros de fe pública encargados de autorizar y guardar en su archivo los instrumentos que ante ellos se otorgaren, de dar a las partes interesadas los testimonios que pidieren, $y$ de practicar las demás diligencias que la ley les encomiende". Por ejemplo, actuar en calidad de receptor para la práctica de notificaciones (art. 58 del $\mathrm{CPC}$ ), la autorización de documentos para otorgarle valor probatorio en conformidad al artículo 342 del CPC, su participación en la protocolización del inventario solemne -842 del CPC-, su función a propósito del testamento, etc.

La doctrina francesa se refiere al notario como un "testigo privilegiado", lo que para nuestro derecho es aplicable si consideramos el artículo 1700 del Código civil al indicar que "el instrumento público hace plena fe en cuanto al hecho de haberse otorgado y su fecha, pero no en cuanto a la verdad de las declaraciones que en él hayan hecho los interesados. En esa parte no hace plena fe sino contra los declarantes". Las consecuencias de la autentificación del acto son múltiples, destacando el carácter de título ejecutivo que le confiere el artículo $434 \mathrm{n}^{\circ} 2$ del CPC a la copia de escritura pública.

Por ejemplo el notario puede realizar las tareas de notificación, aunque solo lo realiza en forma marginal, quedando entregada esa tarea en forma unánime a los receptores judiciales. 
A través la función notarial se describe en gran parte una historia probatoria significativa, al mismo tiempo que se otorga el valor ejecutorio a determinados actos.

Su función se prolonga más allá, siendo necesaria su intervención para variados actos con consecuencias civiles relevantes. El reconocimiento de la filiación no matrimonial -art. 187 no 3 del Código Civil-, en el ámbito de los bienes raíces la excepción son los actos que no deban otorgarse por escritura pública. Así es en la hipoteca, la compraventa, la donación. En estos casos la escritura pública constituye una solemnidad necesaria para la existencia del acto.

Además, deben considerarse aquellas funciones agrupadas en el artículo 401 del COT de variada índole, cuya infracción puede ser fuente de responsabilidad civil.

\section{(1.2) INFRACCIÓN AL MODELO DE BUEN COMPORTAMIENTO: LEX ARTIS NOTARIAL}

Las funciones de los notarios no solo se limitan a cumplir aquellas encomendadas por la ley. En la práctica, los notarios o sus empleados aconsejan modelos para un determinado acto o contrato o sugieren cómo deben realizarse ciertos negocios de escasa cuantía económica. Es una forma de redacción de actos o contratos que suscriben las partes. También el notario opera como un confidente en actos que determinan el futuro de los bienes después de la muerte.

Fuera de la responsabilidad por incumplimiento de deberes legales, los notarios pueden quedar expuestos a responsabilidad por no comportarse como lo haría un buen notario. Algo así como la lex artis de los notarios, que debiera constituir el patrón de conducta que le es exigible aunque no esté prevista la función en forma expresa en la ley. Entonces esta sería una segunda fuente de deberes y obligaciones que es usual que se vaya construyendo a través de la jurisprudencia. Por ejemplo acá debiera plantearse la problemática del deber de información del notario. ¿Es un simple autómata que confirma los aspectos formales? o en determinados casos debiera reparar e informar sobre defectos ostensibles del contrato o de un acto en particular. Si asistimos a infracciones prescritos en la ley, no habrá controversia sobre la procedencia de la indemnización si se confirma un perjuicio. Tampoco debiera existir conflicto para aseverar que si un notario incumple deberes propios a su función construidos a partir de un modelo de comportamiento deberá indemnizar los daños ocasionados. Estos dos aspectos de la responsabilidad civil no se apartan de lo que ha sido la construcción paulatina del hecho generador de responsabilidad. 


\section{2) ¿QUÉ RÉGIMEN DE RESPONSABILIDAD ES APLICABLE AL NOTARIADO?}

En Chile, esta pregunta no ha sido respondida, reina el silencio en torno a cuál debiera ser el régimen de responsabilidad aplicable a los actos u omisiones culpables que causan daño en la esfera del desempeño profesional del notariado. No hay más que dos alternativas: o se le aplica la responsabilidad contractual o aquella aquiliana o extracontractual ${ }^{8}$.

Hay algunas situaciones que son fáciles de discernir a efectos de conocer el estatuto aplicable, mientras que en otras, la discusión podría presentarse.

\section{(2.1) RESPONSABILIDAD AQUILIANA DEL NOTARIO}

Hay dos situaciones en que el régimen aplicable a los daños ocasionados por un acto u omisión del notario corresponderá el estatuto extracontractual.

La primera es aquella en que la responsabilidad civil constituye un accesorio o apéndice de la responsabilidad penal ${ }^{9}$. Si el notario ha incurrido en falsedad autentificando una firma que no correspondía a la persona que haya suscritro el instrumento respectivo, configurándose el tipo previsto en el artículo 193 del Código Penal, para este caso, la víctima del hecho punible podrá optar entre perseguir la responsabilidad contractual, si se asume que existe una relación de prestación de servicios del notario con él, o reclamar por la vía extracontractual los daños ocasionados. Se configura el tradicional problema de la concurrencia de responsabilidad civil, siendo en este caso aplicable la opción a favor de la víctima. Siguiendo una tradición ya bien asentada en la práctica jurisprudencial chilena, la víctima, hoy solo aquella víctima directa del hecho punible, puede demandar los daños en sede penal invocando las reglas extracontractuales, sin perjuicio que haya existido un contrato con el imputado ${ }^{10}$. Se acepta

8 Uno podría acá referirse al ya tradicional problema sobre el estatuto de responsabilidad aplicable a las infracciones legales. Sin embargo, según se afirmará, la opción por la responsabilidad contractual soslaya dicho dilema, pues aun tratándose de normas que prescriben la conducta notarial, el deber se incorporará a la relación contractual. Véase sobre la relación entre ambos estatutos de responsabilidad civil, Barros Bourie, Enrique (2006) Tratado de responsabilidad extracontractual. Santiago: Editorial Jurídica de Chile, p. 18.

9 Sobre esta idea, tempranamente, Domínguez Águila, Ramón (1989) "Aspectos contemporáneos de la responsabilidad civil". Revista de Derecho Universidad de Concepción, $\mathrm{n}^{\circ}$ 185, pp. 107-139, p. 139; más cerca, Barros (2006) 953. Sobre las relaciones entre la responsabilidad civil y penal, Pizarro Wilson, Carlos (2003). "Mirada de un civilista a la reparación en el nuevo proceso penal". Gaceta Jurídica, no 296, pp. 59-75, p. 59 y ss.

10 Las limitaciones a la acción civil fueron impuestas por el artículo 59 del Código Procesal Penal, dejando fuera de las personas susceptibles de ser demandadas en lo civil en sede penal a todas las personas jurídicas, con o sin fines de lucro, y los terceros civilmente responsables que no caigan en la categoría de hecho punible cuando sean personas naturales. 
la opción sin contrapeso a favor del acreedor víctima del delito. Y, también, es usual, que sea el estatuto extracontractual, el que se invoque en sede penal.

La otra situación fácil a discernir es aquella de víctimas por rebote. Es decir, toda víctima que padece un dańo propio a resultas del perjuicio ocasionado a la víctima directa que haya contratado con el notario, deberá necesariamente perseguir la responsabilidad civil invocando el estatuto extracontractual. Si el acto u omisión culpable del notario ha ido más allá del contratante afectando a terceros, por ejemplo al no poder realizarse el negocio previsto por una negligencia en el otorgamiento del instrumento, estos terceros solo invocarán el régimen extracontractual. No existe controversia sobre la pertinencia del estatuto extracontractual al no existir vínculo contractual alguno entre el notario y las víctimas por rebote.

Fuera de estas dos situaciones, es decir en un caso diverso a la responsabilidad civil como accesorio de lo penal y que no se trate de víctimas por rebote, sino del propio sujeto de derecho que concurrió a la notaría a contratar sus servicios, debe dilucidarse si ahí corresponde aplicar las reglas contractuales o extracontractuales.

\section{(2.2) EL RÉGIMEN COMÚN: LA RESPONSABILIDAD CONTRACTUAL}

Aquí surge la interrogante sobre el interés de la distinción. Es cierto que su importancia ha ido decayendo en Chile. Sobre todo una vez que el daño moral ha sido admitido como un rubro indemnizable en el ámbito contractual. Por lo demás, la indemnización del daño moral no es una cuestión especialmente relevante tratándose de perjuicios ocasionados a propósito de la profesión del notariado. Una vez que el espectro de daños indemnizables se unificó, solo quedan como diferencias sustantivas la relativa al artículo 1558 del Código civil, que limita la indemnización a los daños previstos a la época de celebración del contrato, contrastado con la indemnización de todo dańo previsto e imprevisto en el ámbito extracontractual. Sin embargo, esta diferencia normativa no ha tenido una repercusión práctica significativa. La otra distinción sustantiva dice relación con la presunción de culpa que se deriva del incumplimiento contractual en conformidad al artículo 1547 inciso $3^{\circ}$, siendo en terreno aquiliano necesaria la prueba de la misma. Con todo, no pocas voces han manifestado que tratándose de obligaciones contractuales de medio o diligencia no corresponde aplicar presunción alguna, sino que sería el acreedor al igual que la víctima de un daño extracontractual, quien debiera acreditar la falta de diligencia ${ }^{11}$. A esto debe sumarse que si la responsabilidad

11 En esta línea Barros (2006) 430. Vidal Olivares, Álvaro (2010) "Incumplimiento y atribución de responsabilidad en las obligaciones de medio y resultado (a propósito de una sen- 
del notario deriva de la infracción a una disposición legal específica, correspondería aplicar la presunción de culpa según la denominada "culpa infraccional", siendo el notario quien debiera excluir su responsabilidad probando diligencia ${ }^{12}$.

Persisten eso sí diferencias de índole accesorias, como el plazo de prescripción, la capacidad, la necesidad de mora para la responsabilidad contractual e, incluso, de competencia. Quizá la diferencia más relevante, al menos desde una perspectiva práctica, continúa siendo la solidaridad, cuya aplicación es general en el ámbito extracontractual, mientras que en terreno contractual requiere pacto expreso, disposición de la ley o declaración en el testamento.

Por otro lado, el debate sobre la concurrencia de responsabilidad civil no ha sido dilucidado por la Corte Suprema en forma categórica, siendo aún difuso si ante una demanda esgrimiendo las reglas aquilianas, siendo que une a las partes del litigio un contrato, acarrea el rechazo de la pretensión o el juez aprobará la opción de la víctima ${ }^{13}$. Los aspectos procesales, entonces, se unen a la justificación del tratamiento de cuál estatuto es pertinente.

Todo esto justifica entonces determinar cuál sería el régimen aplicable.

El notario interviene cuando lo van a buscar, no es él quien va en busca de prestar sus servicios. Y dichos servicios están enmarcados dentro de las funciones que determina la ley.

¿Qué consecuencias pueden observarse al constatar que los hechos que desencadenan la intervención del notario están determinados por la necesidad del cliente que lo busca para que aquel ejerza sus funciones previstas en la ley a cambio de un pago en dinero? Parece que el aspecto contractual es indesmentible. El notario está obligado a prestar un servicio por ley y el cliente no puede sino recurrir a él para que ejecute dicha prestación a cambio de un precio tarifado. Hay una suerte de contrato forzoso heterodoxo ${ }^{14}$. Es decir, si bien el cliente puede escoger con quien hacerlo y modelar el contenido, necesariamente debe recurrir a un sujeto

tencia de la Corte Suprema no 1.771-2008, en Departamento de Derecho Privado Universidad de Concepción (coordinador): Estudios de Derecho Civil V. Jornadas nacionales de derecho civil. Concepción. 2009, pp. 569-585, p. 569; cfr. Pizarro Wilson, Carlos (2010) "Diligencia, incumplimiento y exoneración de responsabilidad. Comentario a sentencia Corte Suprema no de ingreso 1.771-2007", en Departamento de Derecho Privado Universidad de Concepción (coordinador): Estudios de Derecho Civil V. Jornadas nacionales de derecho civil. Concepción. 2009, pp. 587-593, p. 587.

12 Sobre culpa infraccional, Barros (2006) 142.

13 Sobre la distinción y diferencias entre ambos regímenes, Alessandri Rodríguez, Arturo (1943) De la responsabilidad extracontractual en el derecho civil chileno. Santiago: Universitaria, 716 pp., nº 25, p. 42; Barros, (2006) 18.

14 Sobre esta clasificación, López Santa-María, Jorge (2011), Los Contratos. Parte General. 5a edición por Fabián Elorriaga de Bonis. Santiago: Editorial Jurídica de Chile, 577 pp., p. 140. 
que revista el carácter de notario. Este, por su parte, no puede negarse a prestar el servicio, pues constituye un privilegio y un deber al mismo tiempo desempeñar sus funciones.

Esta posición, contrasta con aquella seguida en Francia donde existe una solución doctrinal y jurisprudencial diversa al entendimiento contractual, pues se privilegia el carácter público del notario, a fin de concluir sobre la naturaleza extracontractual de su responsabilidad. Fuera de la voluntad en la elección del notario, su misión de autentificar emana de la ley, convirtiéndolo en una especie de "agente legal de seguridad jurídica" 15 .

Para el caso chileno, esta solución no parece satisfactoria, pues cumpliéndose con los elementos propios al contrato, la inejecución del mismo debiera ser objeto de las reglas de la responsabilidad contractual. El cliente manifiesta una voluntad destinada a que le presten un servicio, cuyo monopolio está previsto en la ley para la función notarial, pero eso no oculta el carácter contractual del acto. Si bien el notario no puede rechazar la prestación del servicio, eso tampoco nubla la naturaleza contractual, siendo nada más otro contrato de naturaleza forzosa en cuanto al sujeto con quien corresponde contratar.

Desde otra perspectiva, es bien evidente que aquí se verifica un típico caso de concurrencia de responsabilidad civil, terreno privilegiado de la responsabilidad profesional. Luego, uno podría inclinarse a favor de la opción del cliente, o por el contrario, ratificar el principio de la fuerza obligatoria del contrato. Se trata de una cuestión en que la jurisprudencia de la Corte Suprema no ha tenido una posición contundente. De ahí que pueda pensarse para una demanda de indemnización de perjuicios que al constatar una relación contractual debiera invocarse este estatuto al menos en forma subsidiaria.

A esto se agrega, como ya se dijo, el debate sobre el estatuto común de responsabilidad si uno considera que las obligaciones del notario son legales, siendo la fuente de la responsabilidad la ley.

Estas distinciones muestran inquietudes que escapan al análisis particular de la función notarial y que se entroncan con los problemas del régimen aplicable a las negligencias profesionales.

En suma, si bien existen hipótesis no conflictivas en que corresponde aplicar el estatuto extracontractual, al ser clara la relación contractual con el notario para la prestación de un servicio requerido, el incumplimiento en sus funciones debiera desencadenar la aplicación del régimen contractual.

15 Aubert, (2008), 17. 


\section{(2.3) LAS INSTRUCCIONES NOTARIALES}

Una hipótesis particular de ingente aplicación práctica ilustra la posible responsabilidad contractual del notariado. Es recurrente en las notarías el uso de las denominadas "instrucciones notariales". Se trata de documentos que regulan procedimientos para pagos u otros aspectos derivados de la perfección de un contrato, quedando pendiente aún trámites que resultan indispensables para los efectos de dichos contratos. Las partes acuerdan estas regulaciones dejando al notario a cargo de la observancia de la ejecución, lo que marca un momento decisivo para el pago, ya sea por la entrega de dinero o de otros bienes. La particularidad radica en que se trata de un acto jurídico celebrado por las mismas partes de otro contrato ya perfeccionado, cuyas obligaciones o algunas de ellas, están pendientes, siendo el objetivo de las instrucciones garantizar el fiel cumplimiento de las mismas. La satisfacción de dichas instrucciones corresponde a una o ambas partes, cuya realización debe acreditarse ante el notario, quien deberá evaluar su ejecución y solo, bajo esa circunstancia, liberará los fondos retenidos o habilitará su cobro ante un tercero. La función del notario consiste, entonces, en dar por acreditadas las obligaciones derivadas del contrato que se ha perfeccionado ante él, resguardando la plena satisfacción del acreedor. Si bien la hipótesis más frecuente de instrucciones notariales se relaciona con inmuebles, es patente su creciente aplicación para materias mobiliarias de todo tipo ${ }^{16}$. En el evento que el notario falle en la vigilancia del estricto cumplimiento de las instrucciones la responsabilidad civil solo procederá si un notario estándar no hubiera cometido esa desatención o acto negligente. En efecto, al tratarse de una aplicación consuetudinaria ante los notarios, no existe una normativa legal que las cobije, siendo necesario para determinar la responsabilidad del notario, contrastar su actuar con aquel que habría llevado a cabo el modelo de notario o un "buen notario". Es el mismo ejercicio intelectual que se requiere para todo tipo de responsabilidad profesional. Es tarea de los tribunales diseñar ese modelo abstracto de conducta -lex artis- que permitirá inclinarse por el error o la culpa. Si cualquier otro notario hubiera incurrido en ese error, no procederá responsabilidad alguna, mientras que si un notario informado y diligente habría constatado el problema evitando el perjuicio, habrá responsabilidad.

16 El conocimiento de los negocios en que se recurre a instrucciones notariales muy variado y no existe un estudio detallado sobre sus formas y contenido. 


\section{(2.4) LA RESPONSABILIDAD DEL NOTARIO POR EL HECHO DE OTRO}

No todo está resuelto al definir que la regla general será el estatuto contractual si se constatan los elementos de esa fuente de las obligaciones, pues el notario en el desempeńo de sus funciones puede actuar en forma directa o por un funcionario de la notaría, lo que exige el análisis de la responsabilidad por el hecho ajeno o propio.

Si se trata de las hipótesis de responsabilidad extracontractual, la solución parece sencilla, pues el notario es responsable por los actos de sus dependientes en conformidad al artículo 2320 del Código civil, siempre y cuando la víctima logre acreditar que incurrió dicho funcionario en un acto negligente o doloso que causó un perjuicio. Acreditado el vínculo se presumirá culpable al notario quien deberá aportar la prueba de su diligencia, siendo una exoneración de responsabilidad difícil de configurar. En este tipo de responsabilidad se ha transitado desde una responsabilidad por culpa presunta del tercero civilmente responsable hacia una vicaria, es decir objetiva del principal, al menos en el ámbito empresarial ${ }^{17}$.

Respecto a dicho vínculo de dependencia las dudas que pueden surgir son aquellas relativas a si el acto culposo o doloso se ejecuta dentro de las funciones. Sobre todo tratándose de ilícitos penales que pueda cometer un funcionario a espaldas del notario defraudando la confianza de su empleador. La solución debiera ser la misma que para el caso de la responsabilidad del empresario por el dependiente, siendo solo necesario que haya ejecutado el acto ilícito con ocasión de sus funciones, aunque escape a las mismas, pues delinquir nunca estará dentro de sus funciones. Es la misma idea que se ha defendido para justificar la responsabilidad médico por el hecho de otro, siendo el elemento determinante que el funcionario o dependiente haya sido introducido por la voluntad de quien debía ejecutar la tarea o función. En el caso del notariado es más patente, pues dichas funciones le son encomendadas por la ley, y solo él por su voluntad introduce un grupo de personas bajo su subordinación que ayudan a cumplir esas tareas cuyo monopolio legal detenta. No podría entonces excusarse bajo la idea que el funcionario no ejecutó las funciones delegadas, pues fue por su propia voluntad que en la ejecución de las funciones que le son propias intervino este tercero ${ }^{18}$.

En cuanto a la posibilidad de demandar en forma solidaria a ambos, el notario y el funcionario, si bien es discutible la aplicación del artículo 2317 del Código Civil, en atención a que no se trataría de un solo acto

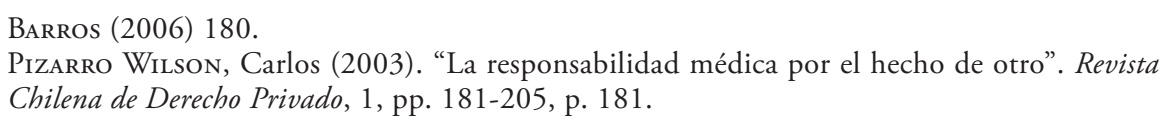


sino de dos ilícitos, siempre cabría el derecho a repetir del Notario contra el funcionario en virtud del artículo 2325 del Código Civil o al estimar que se trata de una obligación in solidum.

En cambio, si el régimen aplicable es la responsabilidad contractual, la responsabilidad por el hecho ajeno en cuanto construcción dogmática parece innecesaria en atención al artículo 1679 del Código Civil que según su texto literal sostiene que "en el hecho o culpa del deudor se comprende el hecho o culpa de las personas por quienes fuere responsable". En consecuencia concurre una garantía del deudor por los actos culposos o dolosos cometidos por los dependientes que hayan participado en la ejecución de sus obligaciones. Aquí se vuelve a una hipótesis de responsabilidad directa a pesar de la intervención de terceros en la ejecución de las obligaciones encomendadas al deudor.

En conclusión, podemos indicar que la problemática de la responsabilidad civil del notariado no tardará a debutar, siendo las causales que justifiquen el pago de una indemnización asociadas a las obligaciones de naturaleza legal y aquellas que se construyan echando mano al modelo de la lex artis del notario. En cuanto al estatuto aplicable, si bien ciertas hipótesis quedan bajo el estatuto extracontractual, la regla general aplicable será aquel de naturaleza contractual en razón del vínculo que une al afectado con el notario. Uno de los aspectos pendientes a estudiar con mayor detención son las consecuencias que se derivan del incumplimiento del notario respecto a las instrucciones que le hayan impartido las partes interesadas. El modelo abstracto de comportamiento del notario sería la forma de resolver si ha incurrido en culpa que pueda desencadenar la responsabilidad civil frente a las partes cuyo acuerdo reflejado en las instrucciones no fue satisfecho de manera apropiada por el notario.

Sin duda, como ha ocurrido en la experiencia comparada, la responsabilidad de los profesionales vinculados al derecho se irá acrecentando, no pudiendo el notariado quedar exento de esta evolución, lo que irá aparejado de los seguros de responsabilidad.

\section{BIBLIOGRAFÍA}

AA.VV. (2010). Responsabilidad médica. Cuadernos de Análisis Jurídico. Santiago: Universidad Diego Portales, $221 \mathrm{pp}$.

Alessandri Rodríguez, Arturo (1943). De la responsabilidad extracontractual en el derecho civil chileno. Santiago: Editorial Universitaria.

Aubert, J.-L. (2008) La responsabilité civile des notaires. 5a edición por Richard Crône. Paris: Defrénois-lextenso.

Baeza Banderas, Enrique (1924) El notario. Santiago: Universidad de Chile. 
Barros Bourie, Enrique (2006) Tratado de responsabilidad extracontractual. Santiago: Editorial Jurídica de Chile.

Crespo Mora, Ma Carmen, (2009) "Daños específicos derivados de la actuación del abogado en el derecho español”, en Revista Chilena de Derecho Privado, 13, pp.101-133.

Henríquez Marino, Óscar (s/a) Nociones generales del notario en Chile. Santiago: Universidad de Chile.

Leyton Guerrero, Cristián (2005) La responsabilidad del notario. Santiago: Universidad Católica de Chile.

Domínguez Águila, Ramón (1989) "Aspectos contemporáneos de la responsabilidad civil". Revista de Derecho Universidad de Concepción, 185, pp. 107-139.

López Santa-María, Jorge (2011), Los Contratos. Parte General. 5a edición por Fabián Elorriaga de Bonis. Santiago: Editorial Jurídica de Chile.

Peña Torres, J. Y Velozo Alcalde, J. (2007). Auxiliares de la administración de justicia: ¿monopolios de privilegio? Disponible en: http://www.economiaynegocios.uahurtado.cl/wp/wp-content/ uploads/2010/06/pdf-observatorio-n7.pdf [fecha de visita 21 de marzo de 2001].

Pizarro Wilson, Carlos (2003). "Mirada de un civilista a la reparación en el nuevo proceso penal". Gaceta Jurídica, no 296, pp. 59-75.

(2003). "La responsabilidad médica por el hecho de otro". Revista Chilena de Derecho Privado, 1, pp. 181-205.

(2010). "Diligencia, incumplimiento y exoneración de responsabilidad. Comentario a sentencia Corte Suprema No de ingreso 1.771-2007", en Departamento de Derecho Privado Universidad de Concepción (coordinador): Estudios de Derecho Civil $V$. Jornadas nacionales de derecho civil. Concepción. 2009, pp. 587593.

Vidal Olivares, Álvaro (2010) "Incumplimiento y atribución de responsabilidad en las obligaciones de medio y resultado (a propósito de una sentencia de la Corte Suprema no 1.771-2008, en Departamento de Derecho Privado Universidad de Concepción (coordinador): Estudios de Derecho Civil V. Jornadas nacionales de derecho civil. Concepción. 2009, pp. 569-585. 